\title{
DISCUSSION
}

\section{VULNERABILITY AND SEISMIC RISK ASSESSMENT OF BUILDINGS FOLLOWING THE 1989 NEWCASTLE, AUSTRALIA EARTHQUARE}

Chandler, Pappin and Coburn

Vol. 24, No. 2, pp116-138, June 1991

\section{R E MELCHERS ${ }^{1}$}

The authors have attempted to use detailed investigation methods in an attempt to make more precise possible conclusions about the damage and risk of damage as a result of the Newcastle earthquake. Such efforts are to be welcomed and no doubt will continue to be made by various observers. It is, therefore, disappointing that the authors(i) chose to misrepresent the findings of the Institution of Engineers, Australia Report to the Government of New South Wales and (ii) are rather careless in certain other respects.

The Report did not claim, as the authors contend, that there was correlation between degree of damage to buildings and depth of alluvial (or filled) soil regions on which such buildings were founded. Such a claim appears in none of the Report's conclusions, nor in the chapter dealing primarily with this issue. On the contrary, the Report noted the complexity of the effect of alluvial soils (p 19):

"In the Newcastle area the dominant influence on the ground motion is almost certainly the effect associated with alluvial deposits and fill. This may be seen by comparing Map 5 upon which are outlined the boundaries of the alluvial deposits and fill in the area with Map 3 showing MM scale damage estimates. Also shown on the map of the alluvial deposits are estimated contours of depth to bedrock. Perhaps of some significance are steep slopes in the underlying bedrock to the NE of the Newcastle Technical College at Tighes Hill, to the E of cooks Hill and along the $S$ edge of the Newcastle $C B D$. In the Beaumont street, Hamilton area a finger of shallower bedrock intrudes into the soft alluvial layers. These are all areas in which surface waves excited by $S V$ waves at the margins of the alluvial areas may be critical. This, however, is speculation and deserves further study".

1 Department of Civil Engineering and Surveying, The University of Newcastle, NSW 2308, Australia
It is the authors' interpretation, not the Report's, that there was correlation with depth. such an interpretation presumably was obtained from a superficial comparison of Maps 3 and 5 on the Report.

Further, the estimates of MM damage given in Map 3 were not claimed to be precise nor exhaustive, but indicative; "the information shown can be considered accurate only to within about 0.5 of the MM scale category, as considerable interpolation of observed damage has been necessary" (italics added). and earlier "it should be noted that the MM scale estimates are subjective and have been interpreted from the inspection reports. The information is, therefore, indicative only".

Although the authors dismiss correlation of building damage with depth (or properties) of alluvial soil, their analysis conflicts with a recently published analysis by Poulos ${ }^{2}$, who notes in his conclusions: "... the extent of damage at a number of sites ... can be correlated with spectral acceleration at the site, and in turn, on the depth of soil and the number of storeys in the structure ...".

Unfortunately the authors' predilection for drawing unwarranted conclusions even extends to their own paper. on page 134 they advance arguments why the damage they have documented in their view has some correlation with the edge of mining activity. They then give an alternative "sociological" argument (really one based on historical development - not sociology) but make no further statements as to which alternative is or was preferred. Yet their conclusion No. 4 (page 137) on this matter is unequivocal -the first alternative is the "correct" one.

Interestingly, the mining argument is based on comparison to the map of Fig. 18 obtained from reference [19]. It conflicts with the map published in I.E. Aust. Report in that no coal extraction is shown along union Street and Glebe Road/Bar Beach Avenue (the North-east and approximately East-west bands in the lower part of Fig. 18). The Mine Subsidence Board has confirmed the Bar Beach Avenue/Glebe Road strip as correct but not the other. There is a strip between adjacent workings, but it runs North-northwest from about the intersection shown on Fig. 18. It is clear that this strip does not correlate at all with building damage.

\footnotetext{
2Poulos, H G (1991), "Relationship between local soil conditions and structural damage in the 1989 Newcastle Earthquake, Australian Civil Engineering Transactions, Institution of Engrs. Aust., $\mathrm{CE}_{33}(3): 181-188$.
} 
Whatever the merit of the argument in favour of correlation between edges of previous mining and building damage, the authors give no explanation why a significant proportion of the damage plotted on Fig. 18 occurred in regions well away from previous mining. Nor do they suggest any plausible arguments why there should be correlation. It should be remembered that the borehole coal seams was generally only $2-3$ metres in depth and at approximately 60-70 metres depth.

Turning now to assessment of structural damage, the authors admit that their database is limited. It is justified by comparison to data supplied by Newcastle City Council. No data was obtained, apparently, for schools, technical colleges, hospitals and other public buildings under the auspices of state or Federal departments. Presumably this means, for example, that the extensive damage at Newcastle Technical College at Tighes Hill was not considered. As will be seen from Fig. 18, this region does not correspond closely to the edge of previous mining activity. Similarly, data for the knitting Mills at Kotara were not considered - here correlation of structural behaviour with alluvial soil presence is possible, but to mining it is not.

In attempting to categorise damage, the authors have considered much detail, yet missed some obvious matters. Thus, structures framed in reinforced concrete are not necessarily less prone to extensive damage, since it is common practice in Australia to clad them with masonry. Depending on the orientation of the masonry relative to ground shaking, the damage can be very similar to that of cavity-brick construction (eg, face loading effects). The structural damage caused to the (at that time uncompleted) Rankin Park hospital is a good example.

Remarkably, the authors virtually dismiss two major factors influencing damage caused by ground shaking - structural deterioration and workmanship. The first factor was significant in many of the older structures. The authors' data show a higher damage rate for these, but they do not explain why this should be the case. There are examples in Newcastle of adjoining identical construction but of considerably different structural condition - the older, deteriorated having failed - but newer part not. It is grossly misleading simply to ignore this aspect and subsume deterioration with earthquake damage ${ }^{3}$.

The earthquake has revealed, particularly for modern construction, that lack of quality of workmanship has been a contributing factor ${ }^{2}$ - this aspect, too, should not be ignored in making comparisons.

It follows, further, that it may be misleading, in the context of the above

${ }^{3}$ page, $\mathrm{A}$, Rleeman, $\mathbf{P}$, stewart, $\mathrm{G}$ and Melchers, R E (1990). "Btructural Aspects of the Newcastle Earthquake". Proc. Second National structural Engineering Conf., Adelaide, I $E$ Aust., pP 305-312. discussion, to make simplistic conclusions about the relative vulnerability of various types of construction (see Conclusion No. 1). Much depends on detailing, on deterioration effects, orientation of buildings relative to ground moving and location relative to alluvial soils.

Some of the commentary in the "Discussion and Implications" section of the paper is speculative or wrong. Further, much of what is correct in this section has been reported already at the conference and in the I.E. Aust. Report [5]. Recommendations were made in the I.E. Aust. Report as to how the Australian standard for earthquake provisions might be revised - but there will not be an 'Earthquake code' as such. It was well-understood and agreed that there will be a loading code dealing with earthquake forces and that each material code separately will deal with resistance requirements.

Cost implications for greater earthquake design requirements were discussed in the I.E. Aust. Report, but emphasis was also placed on education, sound detailing, good inspection and quality control and on the question of deterioration. Many of these matters have little or no cost - they rely on the education of and understanding and awareness by, those involved.

similarly the question of risk in relation to structural design for earthquake conditions and the actions which need to be taken on a number of matters were discussed in some detail in the I.E. Aust. Report. It is not the case, as the paper suggests, that such matters have yet to receive attention. Equally, the dialogue certainly has not closed, but it commenced a good deal earlier than the authors are willing to credit.

\section{AUTHORS REPLY}

The interpretation of damage patterns from the 1989 Newcastle earthquake and their relevance to the assessment of vulnerability and seismic risk to buildings in other areas of low seismicity is clearly a matter of some complexity. our study attempted to determine the possible causes of damage and its distribution, and to identify which of these may have been of primary importance. The study was based firstly on the detailed and more general surveys of damage carried out by the U.K. Earthquake Engineering Field Investigation Team a few days after the earthquake, and secondly on extensive and rigorous follow-up analyses of the damage data. An analytical study of the influence of soil effects on the probable distribution of ground motion within the affected area was also carried out.

With regard to soil amplification effects, it was certainly not our intention to misrepresent the conclusions of the Institution of Engineers, Australia Report. Indeed we were impressed both with the speed of production of this report, and the high quality of the data and analysis contained within it. We have used much of this data in drawing together the conclusions presented in our paper. Conclusion $\mathrm{C} 2.3$ of 
the Institution of Engineers, Australia Report states that there was "a high degree of correlation between areas of significant damage and areas in which the foundation material consists of alluvial soil strata and/or fill". We have taken this to imply that areas of deep soil gave rise to at least as much ground motion amplification as areas of shallower soil deposits, and have referred to the Report as stating that deep soil amplification effects are significant. Professor Melchers is correct in his statement that the Report does not specifically mention depth of soil and we apologise for any misunderstanding we may have caused.

Nevertheless the Institution of Engineers, Australia Report also recommends (R2) a higher level of zoning "for the alluvial soil and filled areas". The local soil site response analyses presented in our paper, and to a large extent the independent studies recently published by poulos as referred to by Professor Melchers, show that only relatively thin soil deposits would be likely to give rise to noticeable amplification effects. In Newcastle these soils are found mostly on the margins of the alluvial basin and the adjacent residual soil areas. Both studies show that on the basis of such analyses it is possible to relate spectral acceleration to the depth of soil (see Figure 17 of our paper and Figure 7 of Poulos 1991). We have also attempted to correlate building damage to soil thickness, as shown in Figure 15 of our paper. It is our contention, however, that in Newcastle such correlations are of somewhat limited importance in comparison, say, with the situation in Mexico City, where in the 1985 earthquake there was a much more obvious link between levels of damage and site amplification effects. This is based on the observation that the distribution of building damage in Newcastle largely reflected the distribution of highly vulnerable older 2 to 3 storey unreinforced brick masonry buildings.

This correlation between distribution of damage and area of highly vulnerable buildings is also cited in our paper in attempting to explain the apparent correlation of building damage with the edges of mining activity. As stated in Conclusion No. 4 of our paper, the most vulnerable buildings in Newcastle were almost invariably situated on the roads dating from the original settlement of the city. The edges of mining activity in many cases appear to be aligned with these roads.

The interpretation made by professor Melchers that we are unequivocally relating the cause of building damage to the borders of mining activity is incorrect; on the contrary our aim was to put forward an alternative explanation for this observation, based on historical urban development.

We are surprised by Professor Melchers' statement that we have dismissed the influence of structural deterioration and workmanship on the earthquake damage, and that we missed the fact that many of the reinforced concrete buildings were clad with brick masonry. These features are apparent from even a cursory survey of damage, and as such we are well aware that they are important factors to be considered in the post-earthquake assessment, as mentioned in several placed in our paper. Whilst such factors were not included explicitly in the damage database developed from the field survey, they are clearly linked closely to the age of construction, and to some extent to building height (for example, reinforced concrete frame buildings were almost entirely multi-storey, and very few brick masonry buildings had more than 4 storeys).

Also, the damage statistics presented in Figures 7 to 9 of our paper were categorised by the Primary Construction Type, which for reinforced concrete frame buildings does not preclude those clad with masonry, as Professor Melchers appears to assume.

In the light of the above comments, it is inevitable that some of the discussion contained in our paper is speculative, which as Professor Melchers himself states is also true of comments made in the Institution of Engineers, Australia Report. Speculation is not in itself unworthy or a matter for criticism, neither can it be termed "right" or "wrong". Rather, our discussion is aimed at highlighting the need for better understanding of earthquake risk, in its broadest sense, in regions of low seismicity such as Australia and the UK. We did not intend to suggest that the process of encouraging the engineering profession in such countries to take steps towards such aims has not already begun, or that it began only recently. 